\title{
Teología de la inocencia: corporeidad, trance e indeterminación en el fidencismo*
}

\author{
The theology of innocence: \\ corporeality, trance and indetermination \\ in the fidencismo cult
}

ALEJANDRA AGUILAR ROS**

\begin{abstract}
This work will focus on the corporeality of the Mexican fidencista cult, through the analysis of the body religious techniques of the materias, the religious leaders that canalize Niño Fidencio, among other spirits. The phenomenological analysis of trance and ludic ritual performances and the highlighting of some central cultural themes that are key to the understanding offidencismo propitiate a fluid and indeterminate corporeality that, in turn, respond to and are a historical byproduct of the context that is Northeast Mexico.

Key words: phenomenology of the body, body techniques, ritual gender, ritual performance, Niño Fidencio, spiritism, spirit canalization, Mexican northeast
\end{abstract}

\begin{abstract}
Resumen
El trabajo se enfocará en la corporeidad del culto fidencista examinado a través de las técnicas corporales religiosas de las materias, los líderes que llevan a cabo los rituales encarnando al Niño Fidencio, entre otros espíritus. Con el apoyo de un marco de análisis fenomenológico del cuerpo y resaltando algunos de los temas culturales centrales que son claves para comprender el fidencismo se estudian el trance y el juego ritual, los cuales propician corporeidades fluidas e indeterminadas, que a su vez responden y son producto histórico de un contexto como el del noreste de México.

Palabras clave: fenomenología del cuerpo, técnicas del cuerpo, género ritual, performance ritual, Niño Fidencio, espiritismo, canalización de espíritus, noreste de México
\end{abstract}

\footnotetext{
* Artículo recibido el 01/10/19 y aceptado el 25/02/20.

** Centro de Investigaciones y Estudios Superiores en Antropología Social (CIESAs), Unidad Occidente. Av. España 1359, col. Moderna, 44190 Guadalajara, Jal. <aaguilar@ciesas.edu.mx>. La autora agradece el apoyo del cIEsAs Noreste durante la estancia de campo en Nuevo León, en 2017.
} 


\section{Introducción}

\author{
No leemos a otros: \\ nos leemos en ellos. \\ Me parece un milagro \\ que algún desconocido pueda \\ verse en mi espejo.
}

José Emilio Pacheco

$L^{2}$ a vida del taumaturgo de Espinazo, N.L., Fidencio Síntora Constantino, mejor conocido como el Niño Fidencio, ${ }^{1}$ perduró gracias al culto que le siguió. Diversos trabajos han indagado sobre su persona, su vida y su obra; se concentran sobre todo en su biografía como curandero, hasta su muerte. Algunos de éstos buscan los detalles contradictorios o aspectos que no se conocen, y otros más buscan documentar sus milagros y curaciones para fundamentar su fama y la verdad de su taumaturgia, la cual practicó de 1920 a 1938 en Espinazo (Berlanga, Lara y Ramírez, 1999; Garza Quirós, 1974; González Vidales, 1970; Macklin, 1967; Monsiváis, 1995; Zavaleta, 2012, 2016 y 2018).

Es a partir de estas biografías que se sabe que sus seguidores eran los pobres entre los pobres y que parte de su fama fue precisamente su compasión por ellos. En respuesta a la difusión de su culto, se habla del contexto de pobreza en el noreste posrevolucionario, el abandono de las instituciones de servicios básicos como educación y salud, así como la poca presencia de la Iglesia católica en el contexto de la guerra cristera, sin dejar de lado el papel que los medios de comunicación -como el tren y los periódicos que buscaban unificar al país- tuvieron para difundir la fama de Fidencio como curandero (Agostoni, 2018; Arias y Durand, 2009).

Hay, sin embargo, pocos trabajos sobre el fidencismo actual: ya sea sobre sus seguidores, sus prácticas o la Iglesia que fundaron más adelante los descendientes de los parientes adoptivos de Fidencio (De Ita Rubio, 2018; Farfán, 1997). Son mucho menos aquellos trabajos que tratan la intimidad de las experiencias religiosas de los fidencistas, a pesar de su marcada expresión corporal en el trance.

En este trabajo exploraré algunas de las experiencias corporales de los dirigentes fidencistas llamados cajitas, materias o vasos, hombres y mujeres que canalizan el espíritu de Fidencio entre otros más, para llevar a cabo diversas funciones, sobre todo de curación, entre sus comunidades de fieles (nombradas misiones o columnas).

El foco principal de este trabajo será visibilizar, con datos etnográficos, las prácticas corporales fidencistas, que permiten circular el conocimiento del fidencismo en una feligresía que se compone mayoritariamente-pero no de manera exclusiva-de seguidores que podríamos calificar de marginales. Me apoyaré en Jackson (1983) y Csordas (1990, 1994 y 2010) para trabajar sobre la corporeidad fidencista. En la primera parte relataré con brevedad cómo se estableció la Iglesia y su culto a partir de la muerte de Fidencio, para instituirse, de modo central, como culto espiritista. En la segunda parte dialogo con Csordas (1990 y 2010) y Jackson (1983) para desarrollar una comprensión más precisa de una fenomenología desde el cuerpo, y así entender lo que llamo corporeidades religiosas; es decir, formas expresivas corporales que denotan maneras particulares de experimentar lo religioso. Subrayo que el culto puede comprenderse mejor desde lo que nombro temas culturales, tomados a partir de las prácticas corporales (Mauss, 1979). En la tercera parte me adentraré en los temas de trance, purificación y corporalidades fluidas en el fidencismo, con el objetivo de comprender algunos ejes de la corporeidad fidencista para, finalmente, a modo de conclusión, entender esas corporeidades en un contexto como el del noreste mexicano.

\section{Estructura y organización del fidencismo}

El movimiento que se derivó después de la muerte del Niño Fidencio ha sido poco tratado y referido principalmente como corolario de su herencia espiritual; su estructura y sus prácticas han sido estudiadas por pocos (Farfán 1997; Zavaleta, 2018), aunque fotografiadas por muchos (Pedro Valtierra y Gustavo Casasola, entre otros). Se dice que Fidencio profetizó que no iba a morir, sino a regresar pronto, y al parecer lo cumplió, pues, en cuanto murió, una de sus seguidoras tuvo un estremecimiento y comenzó a hablar como él, abriendo así el camino a su espíritu por medio de su canalización.

\footnotetext{
1 Nació el 13 noviembre 1898, en Iramuco, Gto. y falleció el 19 octubre 1938, en Espinazo, N.L. (población del municipio de Mina, ubicado a $94 \mathrm{~km}$ en dirección al noroeste de la cabecera municipal). Si bien Fidencio era ya un adulto cuando su fama se extendió, todo parece indicar que padecía el síndrome de Klinefelter (cf. Zavaleta, 2012), el cual no le permitió desarrollar caracteres sexuales secundarios; el apodo le viene de sus seguidores, que lo consideraban tan inocente como un niño.
} 
Los primeros canalizadores fueron Damiana Martínez -reconocida entre sus seguidores como "vocina (sic) principal", ${ }^{2}$ o "directora"-y Víctor Zapata, quien se encargó de ser el "inspector general”, denunciando a quienes tenían "voces falsas", o no eran realmente canalizadores de Fidencio. ${ }^{3}$ Entre 1925 y 1938, los fidencistas recopilaron junto con Zavaleta (2013) las enseñanzas del Niño, recolectando más de setenta. Estas enseñanzas se convirtieron después las bases éticas del fidencismo y se compilaron en el "Evangelio de Fidencio".

Damiana y Víctor fueron también responsables de la difusión del culto en los años cuarenta y cincuenta. En la década de los setenta el culto ya se había establecido, con una liturgia básica y las visitas bianuales a la tumba de Fidencio en lo que fuera su casa, actual santuario, en Espinazo, los meses de marzo y octubre, para celebrar su onomástico y conmemorar su muerte. La hija de Víctor Zapata, Panita, fue la líder del culto hasta su muerte en $2008,{ }^{4}$ junto con Fabiola, una de las hijas de Enrique de la Fuente, la familia que adoptó a Fidencio y para la cual él trabajaba.

En los años noventa, con el cambio constitucional entre las relaciones Estado-Iglesias, los hijos de Fabiola registraron el movimiento ante la Secretaría de Gobernación con el nombre de Iglesia Fidencista Cristiana (IFC). Con este registro, se produjo un cisma por el que ambas lideresas se separaron y los seguidores de Panita quedaron como fidencistas independientes.

En la IFC, Ariel de la Fuente, hijo de Fabiola, es quien lleva el control y registro de las materias, ofreciendo capacitación y guianza espiritual. Las materias deben pagar una cuota mensual y están obligadas a capacitarse en los cursos anuales por los cuales también se paga una cuota. La familia De la Fuente es dueña de la casa-santuario en Espinazo. ${ }^{5}$ Por otro lado, los fidencistas independientes no se afilian a la IFC, ni pagan cuotas, y acuden por su cuenta a Espinazo. Los más críticos al sistema de cuotas de la Iglesia organizada son las materias que vienen de Estados Unidos, quienes de manera sistemática se niegan a pagarlas.

Aunque desde una perspectiva sociológica puede analizarse como Iglesia desde su institucionalización, me parece más adecuado considerarla un movimiento religioso independiente por la forma en que se estructura y reproduce socialmente. Se organizan alrededor de las materias en lo que llaman misiones, columnas o tronos, por lo general los fines de semana -aunque puede haber misiones que se reúnan con más frecuencia. Estas misiones están extendidas sobre todo por los estados del noreste de México (Nuevo León, Coahuila, Tamaulipas) y sureste de Texas, pero también en lugares donde la migración agrícola de los años treinta y cuarenta ha sido significativa como Guanajuato, San Luis Potosí y los estados de la Unión Americana de Indiana, Ohio, Michigan, Colorado, Washington y Oregón (Zavaleta, 2018).

Los cultos domésticos se fundamentan sobre todo en curaciones, rezos y cantos. Un cargo importante en el culto doméstico son los cuidadores o guardianes, quienes atienden a la materia durante el trance, o en las festividades; se encargan de preparar la "reliquia", la ofrenda que los asistentes dejan para la materia (monedas, comida). Otro cargo relevante, dependiendo de qué tan grande sea la misión y su trascendencia, es el de cantador. Los fieles se autonombran misioneros, pero también hay otro tipo de seguidores, que pueden ser católicos devotos y a la vez atender el culto fidencista, quienes consideran al Niño Fidencio como una devoción más. La Iglesia fidencista sigue el calendario litúrgico de la Iglesia católica, y en muchos aspectos la liturgia es semejante, pero para el catolicismo se trata de un movimiento inadmisible, sobre todo por la canalización de espíritus.

\section{De las técnicas corporales a la intersubjetividad del embodiment}

Los cultos fidencistas se destacan por su corporeidad. En particular sobresale el uso del trance como medio de comunicación tanto con el mundo de los espíritus como entre los fieles y la enseñanza del fidencismo. Para examinarlo y aproximarme al culto en general encuentro pertinente situarme en un análisis fenomenológico del cuerpo.

Los trabajos sobre cuerpo tienen su asiento fundacional en el ensayo seminal de Marcel Mauss (1936) sobre las técnicas del cuerpo, donde muestra que las prácticas corporales son moldeadas culturalmente. Tanto en la antropología como en la sociología estas aproximaciones han buscado comprender "maneras de hacer corporales" contextualizadas, y han desarrollado sus análisis en especial desde perspectivas simbólicas.

\footnotetext{
2 "Bocinas", "materias", "cajones" o "cajitas" han sido los nombres que se le ha dado a los canalizadores de Fidencio. Aquí utilizaré sobre todo el término materia, ya que es ahora el más común.

3 Fidencio mismo había anunciado que habría seguidores falsos y sus discípulos estaban ya alertados de esto.

4 Cipriana Zapata Robles, hija de Víctor, quien murió el 25 agosto del 2008.

5 Algunos estudiosos del fenómeno fidencista mencionan que su culto posterior se debió sobre todo a intereses creados por la familia De la Fuente alrededor de la figura de Fidencio (Zavaleta, 2018).
} 
Una fuerte crítica a estos acercamientos proviene de los enfoques fenomenológicos, que señalan el peligro de interpretar desde el constructo cultural del analista, asumiendo que se realizan en la postura "objetiva" del mismo. Estos trabajos han dado un giro fundamental en el que se ha pasado de un análisis sobre el cuerpo a la búsqueda de comprender desde el cuerpo. En el campo de los estudios de la religión, gracias a estas corrientes, surgen a la vez cuestionamientos sobre el concepto de creencia, pues, como han notado varios analistas, éste tiene una aplicabilidad limitada principalmente por no ser una realidad universal, sino más bien un producto histórico del cristianismo-de manera señalada en sus corrientes protestantes-, que reifica una oposición entre la creencia particular y su expresión social externa, llevándonos al problema clásico -y falso-individuo vs. sociedad (cf. Chua, 2011: 11).

Los análisis fenomenológicos (Jackson, 1983) buscan comprender las experiencias de los sujetos, más que las creencias -que nos refieren al aspecto cognitivo-, encontrando en las metodologías intersubjetivas un acceso a la experiencia religiosa. Desde esta perspectiva, tales metodologías me parecen más adecuadas para acercarse al cuerpo, o a las corporeidades, término con el cual prefiero posicionarme, como explicaré más adelante.

Dos autores son claves aquí: Michael Jackson (1983) y Thomas Csordas (1990, 1994 y 2010), quienes nos proponen comenzar con el cuerpo, para pasar a la contextualización del mismo, más que terminar (en la interpretación) sobre el cuerpo, lo cual es mi pretensión en este texto.

Jackson es de los primeros antropólogos en esbozar una crítica clara a las formulaciones meramente simbólicas, a partir de su propio trabajo entre los kuranko de Sierra Leona. Su crítica es severa frente a la "tendencia [que] considera las prácticas como 'simbólicas', fuera de ellas mismas" (Jackson, 1983: 328 , de aquí en adelante, traducción de la autora), e interpreta la experiencia corporeizada en términos de modelos cognitivos y lingüísticos (Jackson, 1983: 328). El cuerpo, nos recuerda, informa más allá de estos modelos lingüísticos, ya que el signo no está fuera del dominio del acto (Jackson, 1983: 328); ${ }^{6}$ después de todo, los rituales, más que pertenecer a un dominio discursivo de creencia, pertenecen a dominios de actividad práctica (Jackson, 1983: 333). Por lo tanto, el análisis debe resonar con los conocimientos autóctonos, los cuales con frecuencia están insertados en las prácticas, más que en las ideas (Jackson, 1983: 339).
Jackson delinea un proyecto antropológico desde el cuerpo como un cuerpo que "se vive" más allá de los modelos semióticos; es activo, no pasivo, y conoce su entorno e interactúa con él. Para romper con el análisis lineal de comunicación (donde el antropólogo tiene la última palabra), una estrategia metodológica sería situarse, en la medida de lo posible, en el lugar de los otros, habitando su mundo y tratando de comprenderlo saliendo de la observación participante hacia una comunicación intersubjetiva, mediante la comprensión de las articulaciones intermediarias (intermediary links) que se utilizan en los diferentes "medios ambientes desde donde se actúa" (environment of a way of acting) (Jackson, 1983: 332).

Su proyecto es, entonces, una fenomenología de la experiencia corporeizada (embodied experience) que se "arraiga en el movimiento del cuerpo y que privilegia lo que sucede entre las prácticas corporales -hábitos del cuerpo- y las convenciones sociales del campo social y el mundo material en el que la gente actúa" (Jackson, 1983: 327).

Suscribo junto con Jackson que el carácter convencional de los hábitos corporales, más que el resultado de la obediencia a reglas sociales, es la consecuencia de la manera en que los cuerpos son informados por hábitos aprendidos en un medio ambiente compartido -y, agregaría, histórica y contextualmente-, condicionados por una relación con los otros y con los objetos. Las representaciones colectivas de género y clase estarían entonces correlacionadas con los patrones corporizados generados por el habitus (Bourdieu, 1977), originando un "set" de hábitos corporales que se refuerzan con el medio ambiente en que éstos se arraigan (Jackson, 1983: 334). Aun así, este set de prácticas y disposiciones corporales, ideas y experiencias puede romperse e inducir a nuevas experiencias e ideas, lo cual permite a su vez cambiar la disposición corporal. El trance, sugiero, podría entenderse como posibilidad de disposición corporeizada que no se expresa de manera cotidiana, pero que abre enormes posibilidades para el habitus cotidiano y que se aprende como una performance mimética del contexto donde aparece (Jackson, 1983: 335).

La distinción radical que hace Jackson entre interpretación y práctica encuentra más tarde un camino metodológico en la elaboración del trabajo de Csordas (1990, 1994 y 2010), con dos conceptos: modos somáticos de atención y embodiment. En una cita, por demás famosa, Csordas sitúa al cuerpo como "el locus existencial de la cultura" (1990: 5),

\footnotetext{
6 Un problema derivado de los modelos lingüísticos es no darle centralidad -y veracidad-al cuerpo que "conoce": el cuerpo no
} puede ser tratado como mero signo de lo social, donde se reflejen los patrones sociales (Jackson, 1983: 329). 
señalando así la participación epistémica central del cuerpo en la percepción del mundo, sin el cual no es posible conocerlo (embodiment). Csordas argumenta a favor de un re-análisis de los datos etnográficos no de los cuerpos, sino desde los cuerpos, y aboga por la comprensión de la percepción a través de las prácticas arraigadas en el cuerpo socialmente informado (Csordas, 1990: 7); es decir, aunado al "mundo donde se actúa" de Jackson, la experiencia corporizada (prácticas y percepción del mundo) es el punto de partida para analizar la participación humana en el mundo cultural (Csordas, 2010: 83).

Considero que prestar atención o "traer el objeto a la existencia" (Csordas, 2010: 86) establece articulaciones con el objeto/sujeto, realizando un "compromiso corporal" hacia el mundo. Comprometer el propio cuerpo en un proceso de objetivación incluye, por lo tanto, prestar atención a los otros y a sus cuerpos (Csordas, 2010: 88) desde el propio cuerpo. Estos modos de atención son culturalmente determinados y no deberíamos darlos por sentado.

Se propone, entonces, repensar los fenómenos culturales desde el ángulo de la intersubjetividad corporizada e incorporar al análisis las categorías mismas de la experiencia de los sujetos y moldear las descripciones en términos de modalidades sensoriales (Csordas, 2010: 96-97) -las disposiciones corporales de Jackson-, reconociendo que los polos de descripción entre "cognición" y "afecto" no son suficientes para capturar la naturaleza intersubjetiva de los fenómenos sociales y, en consecuencia, poseen un principio de indeterminación subjetiva, permitiendo que las categorías de análisis no tengan que ser fijas, duales, o sólo empíricas.

En suma, las posiciones fenomenológicas de los dos autores sugieren metodologías intersubjetivas y corporizadas desde el cuerpo del propio investigador, donde el conocimiento obtenido y las categorías del análisis provengan, sobre todo, de los mismos actores y de la interacción con el o la antropóloga, para comprender cómo se dan las disposiciones corporales en contextos históricamente situados, que no son fijos, sino fluidos, indeterminados y en constante diálogo cuerpo/s-contexto. Considero que un examen de este tipo nos permite tomar el trance y todas las experiencias religiosas como fenómenos que no necesitan ser "explicados" ni en términos de lógicas cientificistas, ni simbólicas, sino en la posición de comprender modos de expresiones corporales que se manifiestan en la religión y atienden a su propio entorno, articuladas por perspectivas nativas tanto religiosas como no religiosas (Csordas, 2010: 95). Siguiendo una lógica fenomenológica sobre "el cuerpo", me posiciono ade- más, en el sentido de que en el fidencismo no es posible sostener la idea de una sola identidad equiparable a un solo cuerpo. En este trabajo no puedo extenderme sobre el concepto de corporeidades (Aguilar Ros, en prensa), pero utilizaré preferentemente dicho término para distinguirlo de "cuerpo" como unidad diferenciada y referida a un solo sujeto. Corporeidades, además, remite a los aspectos culturales contextuales que moldean las disposiciones corporales, manifestándose de maneras cultural e históricamente situadas.

Las preguntas pertinentes para un estudio fenomenológico del cuerpo serían ¿qué se hace con el cuerpo y en qué contexto? O, aún mejor, ¿qué tipo de corporeidades se producen y en qué contexto?, ¿qué tipo de conocimientos atienden estas corporeidades socialmente informadas? y, ¿cuáles son los modos sensoriales que permiten estas corporeidades?

Cuando uno revisa las prácticas corporales en el fidencismo, si bien la sanación aparece como un tema central, del modo en que lo muestran quienes lo estudian, también surgen otros temas culturales que provienen de las materias fidencistas mismas.

En el fidencismo, el cuerpo propio se convierte, en efecto, en un objeto (Csordas, 1990: 6) para la materia, quien permite que Fidencio u otros espíritus entren en su cuerpo. Aquí, los espíritus interactúan de modos intersubjetivos con la conciencia y el cuerpo de la materia, dejando que el espíritu en cuestión resuelva los problemas de sus fieles.

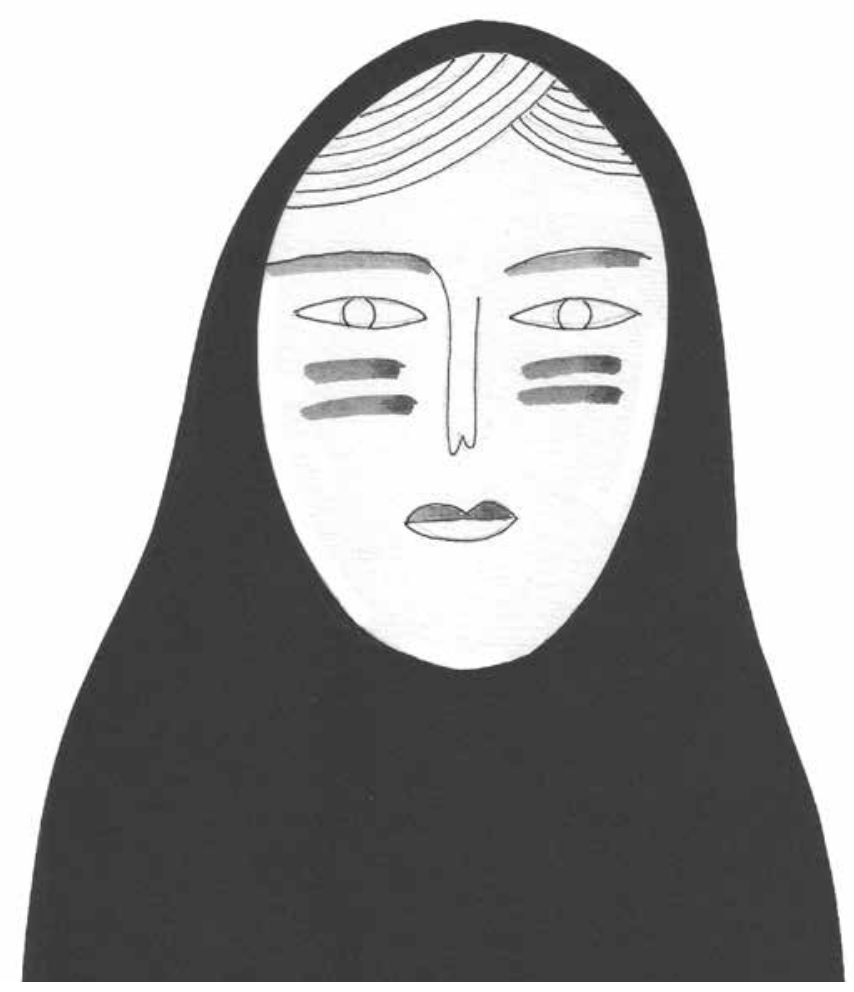


En lo que sigue, trazaré, sin agotarlos, algunos temas culturales que he identificado a través de la convivencia con estas materias. El tema del trance y sus técnicas corporales es el principal, pues de él se derivan los dos siguientes: la actitud de "ser niño" o inocente, y el sistema de género reivindicado en el contexto del norte. Aquí, entiendo el trance como un medio de expresión subjetiva y contestataria, así como de transmisión de la práctica y conocimientos fidencistas; da lugar a expresiones emocionales desde las relativas a la pureza y la inocencia, hasta expresiones identitarias de género alternativas.

Esto me ayuda a situar el fidencismo como un movimiento religioso que privilegia el cuerpo y permite manifestaciones que en el contexto del noreste mexicano se salen de la normatividad, en una indeterminación corporal que puede comprenderse mejor desde las prácticas corporales de sus practicantes. Para situarme en este diálogo intersubjetivo, me coloco aquí como antropóloga entrenada en rituales y religión, nacida como católica, y alejada de la institución. Me interesa la vivencia religiosa, sobre todo desde el ritual y las experiencias sociales e intersubjetivas que éste provoca. No puedo decir que he entrado en trance, aunque lo he intentado y tal vez estuve cerca de ello, pero no lo sé a ciencia cierta. No alcanzo a comprender cómo es que pueden canalizarse espíritus, pero, al ser una técnica de conocimiento transcultural, como antropóloga no cuestiono su autenticidad, a menos que esta posibilidad surja de entre los mismos participantes. Este contexto personal signa a la vez los temas culturales que detallaré.

\section{Trance, purificación y corporalidades fluidas}

Farfán (1997) identifica en el fidencismo lo que denomina un "modelo de curación fidencista", el cual "ha sincretizado en su práctica, ideas, creencias y terapéuticas de la medicina tradicional, del catolicismo popular y del 'espiritismo moderno"' (1997: 32). Sin embargo, dejar sólo en la terapéutica este movimiento aparta aspectos destacables que podrían revisarse para comprender mejor su complejidad.

El trance es el medio principal para comunicarse con los espíritus y obtener su guía, por lo que, si bien la sanación es la práctica fidencista por la que los seguidores van a los cultos, el trance es el medio por el que se realiza la transmisión de saberes y de legiti- mación, ya que perpetúa la presencia de Fidencio, y actualiza las enseñanzas a sus seguidores.

El "llamado" a ser materia se da si alguien "tiene luz" y puede ser para cualquiera, incluso niños, y puede suceder en las reuniones de las misiones o a través de sueños, pero siempre está vinculado con el trance. Es el Niño quien puede despertar "el don", el cual en ocasiones se tiene desde el nacimiento. De ser así, la materia que decide serlo entrará en una etapa de aprendizaje de las tradiciones fidencistas de forma oral, la herbolaria para las sanaciones y, lo más relevante, cómo entrar y salir del trance, junto a otras materias más experimentadas. A estos neófitos se les llama desarrollos (Farfán, 1997: 34-35), quienes culminan su preparación con una ceremonia de coronación, llevada a cabo en Espinazo.

La materia comienza el ritual de sanación entrando en trance, permitiendo por medio de rezos y canciones que se apodere de ella el espíritu de Fidencio. Las materias entrevistadas reportan sentir que "viene el trance" y hacen referencia a "abrir sus cuerpos" y a tener sensaciones corporales como frío, calor o sentir la piel erizada, especialmente con algunos cantos que les son muy queridos, ${ }^{7}$ o que son tradicionales para entrar en el trance, donde las materias corporeizan a Fidencio mismo: su tono de voz, sus gestos enuncian sus enseñanzas espirituales, sus consejos, y alcanzan sus dotes de adivinación o telepatía, así como su compasión y dulzura (Farfán, 1997: 33-34).

Otros espíritus pueden también ser canalizados: Pancho Villa, que se encarna vestido de revolucionario, con carrilleras, sombrero, pistola y tequila en mano; la gitana Margarita Catalán; la compañera de juegos de Fidencio, Aurorita Prado Quintanilla, mejor conocida como Niña Aurorita; pero también otras divinidades como el Santo Niño de Atocha (vestido como tal y en ocasiones llamado Tocho), y otros que sé de ellos por relatos, pero no he sido testigo, como la Virgen de Guadalupe, Santo Toribio Romo y San Cipriano, o Chuyito -también un Santo Niño pero de diferente versión que el de Atocha y concebido como entidad diferenciada. Pancho Villa, la gitana Margarita Catalán y el Santo Niño de Atocha son los más comunes. Solamente Pancho Villa y Margarita Catalán son adultos, el resto de los espíritus, incluido Fidencio, son niños y todos son personajes ahistóricos, a excepción de Pancho Villa y del propio Fidencio.

En los cultos domésticos la materia suele realizar primero un ritual colectivo de bienvenida a los asistentes, para luego curar uno por uno a los pacientes

\footnotetext{
7 Uno de ellos es "Fidencio Constantino, mi corazón te llama, porque tú sólo sabes como al señor se le habla...". Para las materias, es un canto emotivo y emocionante, que conecta directo con la experiencia del trance.
} 
que lo soliciten. La materia hará preguntas al paciente, lo consolará y lo curará a través de masajes, barridos o limpias -en ocasiones intervenciones quirúrgicas de carácter espiritual-, también puede prescribirle un remedio de hierbas, y por lo general debe regresar al templo doméstico varias veces. El trance de la materia puede durar desde un par de horas hasta días, dependiendo de si es un culto semanal o es alguna festividad. En las fiestas en Espinazo el trance puede durar varias horas continuas, ya que el ritual de llegada ${ }^{8}$ puede iniciar desde muy temprano y terminar hasta muy avanzada la noche. Los espíritus pueden entrar y salir del cuerpo de la materia varias veces durante este lapso.

El trance puede, asimismo, ser experimentado entre los participantes. He registrado que es posible que quienes los tienen lleguen a curar a otros en sueños. Es en el estado de trance que los seguidores saben que Fidencio o los demás espíritus han llegado para curarlos. Si la materia está "bien conectada" a Fidencio ella canalizará bien sus mensajes y dará diagnósticos certeros, así como mensajes que realmente se acerquen a la condición de los pacientes. "Según su elevación" será una mejor materia, como me dijo Paco, una materia con más de 60 años de experiencia en canalizar a Fidencio. ${ }^{9}$ No obstante, aun tratando con espíritus, las materias buscan un lenguaje terrenal: "Como personas materiales que somos, necesitamos que nos consuelen, y que nos den soluciones materiales y espirituales". ${ }^{10}$

Durante las fiestas en el santuario, las materias van recorriendo el lugar deteniéndose a realizar rituales en sitios clave, donde continuamente caen en trance, como en el Pirul, un árbol considerado sagrado ${ }^{11}$ a la entrada del santuario. Luego en procesión, algunos rodando, llegan al santuario/casa de Fidencio, donde oran frente a su tumba, para pasar después, en la misma casa, a un área amplia con una tarima, donde Fidencio llevaba a cabo obras de teatro. Ahí celebran una liturgia -muy parecida a una misa católica- liderada por la materia principal, quien se acompaña por varios de los seguidores cercanos, quienes pueden caer en trance o no. Al terminar, cruzan el salón para subir a otra tarima en un segundo piso, desde donde arrojan frutas y dulces a sus seguidores; bailando, bajan y tocan a los feligreses, otra forma de hacer curación. Después de la liturgia y el ritual de sanación con fruta y danza, la misión hace una comida de convivencia. Más tarde pueden ir al "Charquito"12 para seguir haciendo curaciones.

\section{Foto 1}

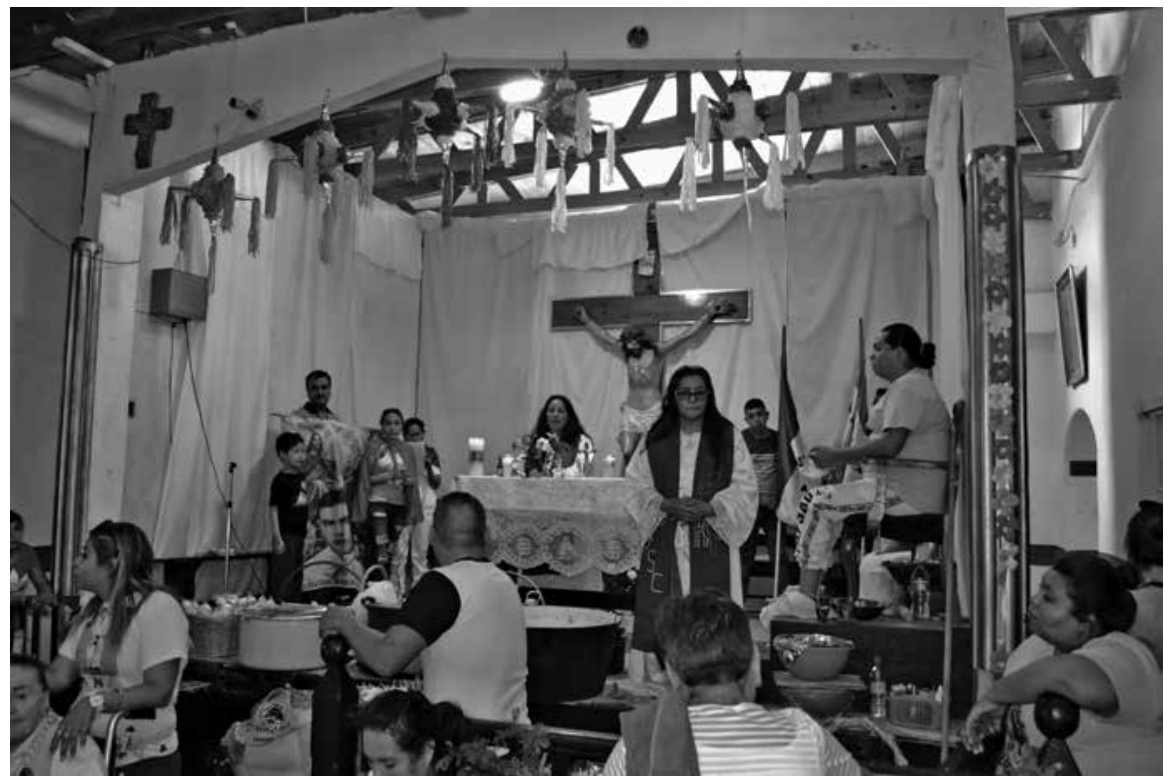

Materia en trance, oficiando una misa en Espinazo, N. L. Foto: Luis Germán Ríos, marzo 2018

8 Para una descripción detallada de espacios rituales en Espinazo, véase Carrizales Márquez (2018).

9 Entrevista a Paco, 18 marzo del 2018.

${ }^{10}$ Entrevista a Paco, 18 marzo del 2018.

${ }^{11}$ Fidencio tomaba de las hojas para curaciones.

${ }^{12} \mathrm{El}$ Charquito es una pila de agua, que parece sulfurosa: oscura, lodosa y con olor fuerte. Este lugar es donde los fotógrafos que han seguido al fidencismo ponen su foco, por lo impactante que resulta. 


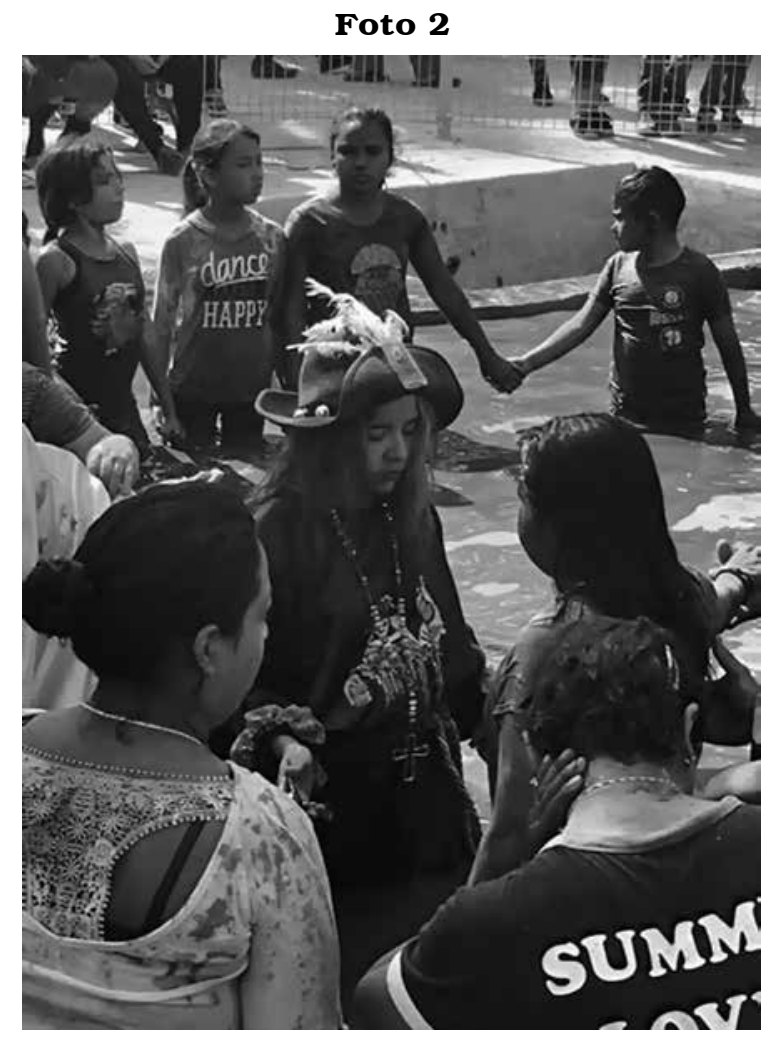

Materia del Santo Niño de Atocha, sanando en el Charquito

Foto: Alejandra Aguilar Ros, marzo 2017

El amanecer del segundo día es otro momento de la fiesta, cuando se hace un ritual en el Cerro de las Campanas, ${ }^{13}$ a la entrada de Espinazo, donde hay varias cruces pertenecientes a las misiones (véase foto 3). Cuando junto con mi compañero visité este lugar fuimos recibidos con mucha suspicacia por parte de las misiones. Al vernos, una materia solicitó a su grupo no abrir el círculo a fin de que no entraran otras personas y, en medio de la discusión, pidió que con un listón rojo y rezando el salmo 91 para protección, se cercara el ritual de sanación ahí efectuado. Las materias dicen estar menos protegidos ahí, y aseguran tener mucho cuidado para que no entren o no se "mezclen" otras energías, ${ }^{14}$ ya que algunos trabajan con espíritus que "no son buenos", y efectuan rituales de magia negra. Las materias insisten mucho en que éstas deben ser puras, adheridas a las enseñanzas de Fidencio, y trabajar con valores como obediencia, entrega, sacrificio y sin apegos al dinero o al poder.

$\mathrm{El}$ trance es la base en la que se reta o se legitima la autoridad: es el núcleo de controversias y, al mismo tiempo, donde se resuelven las diferencias entre los distintos grupos. Para los más experimentados, el "don" debe saber desarrollarse y cultivar, pues las materias "pueden no estar bien cimentadas con educación"; ${ }^{15}$ es decir, el fidencismo y su doctrina es algo que debe seguirse estudiando, ya que "los actos materiales de cada materia pueden distorsionar o aumentar la energía”. ${ }^{16}$ La materia, entonces, puede "quemarse pronto" si no cimienta esta forma de canalizar la energía, o si pasa demasiado tiempo manifestándose ante otros, sin realmente hacer estudios profundos sobre el fidencismo. Paco, la materia experimentada referida arriba, mencionó que Fidencio incluso le habla en sueños y de ahí él aprende. En ocasiones puede ser que no sepa lo que hizo Fidencio, pero en otras puede hablar con él mientras ocurre el trance. Durante la entrevista, Paco insistió en que el fidencismo tiene una filosofía y que ellos como materias viven de manera íntima con Fidencio, de modo que logran tener conocimiento profundo de sus enseñanzas. Por ello aseguró que no todas las materias y no todas las enseñanzas $u$ órdenes que da la Iglesia fidencista (IFC), dirigida por Ariel, son válidas. A pesar del llamado "Evangelio de Fidencio", al que aludimos antes (Zavaleta, 2013), de donde se propagan las creencias centrales del fidencismo, un tema continuo entre las materias es estar seguros de si Fidencio habla por ellas o no; lo que significa que el asunto de la legitimidad de la enseñanza siempre está presente, por más oficialización que exista por parte de la IFC. La canalización en el trance permite un ámbito de indeterminación que, justamente, se manifiesta en la subjetividad de cada materia y la relación que tienen con sus espíritus canalizadores. Este ámbito de indeterminación jugará siempre un papel de ambigüedad, de espacio abierto donde, como veremos a continuación, lo lúdico tiene lugar.

\section{La inocencia y el juego: ser niño para ser puro}

Durante el trance, las materias realizan una performance donde puede reconocerse que es Fidencio quien aparece. La gestualidad particular con la que se manifiesta siempre remite a un niño: la voz de las materias se hace aguda, mimosa, se entrecierran los ojos, pero, sobre todo, hay mucho juego, risas y baile. La gestualidad corporal depende de a quién se canalice, y ayuda además a saber qué espíritu aparece, ya que

\footnotetext{
${ }^{13}$ En este cerro se decía que Fidencio iba a orar y se sigue utilizando para diferentes rituales de las misiones.

${ }^{14}$ Este discurso no sé si es reciente por la influencia new age actual, o si siempre se ha hablado así.

${ }^{15}$ Entrevista a Paco, 18 marzo del 2018.

${ }^{16}$ Entrevista a Paco, Irma Gerardo, 18 marzo del 2018.
} 


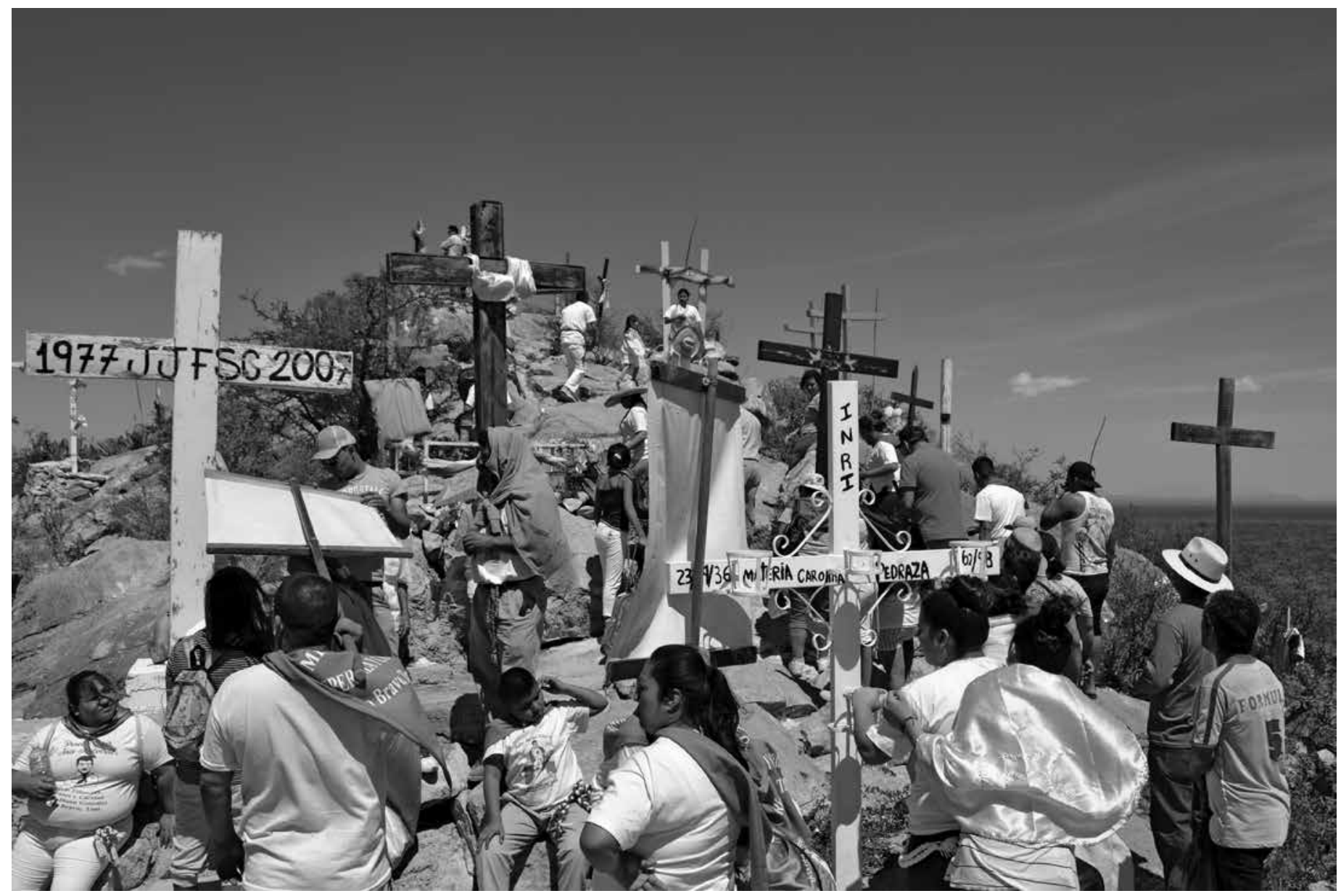

Materias realizando rituales en el Cerro de las Campanas, Espinazo, N. L.

Foto: Luis Germán Ríos, 18 marzo, 2018

un mal canalizador puede atraer espíritus que no son buenos, o de baja energía.

Tanto la corporalidad de Fidencio como de la Niña Aurorita o la del Santo Niño de Atocha son niños, de modo tal que, por lo común, las materias bailan y juegan con los asistentes, reparten dulces y son muy cariñosos. Este "ser como niños" permite que la materia pueda moverse con mucha libertad, que hable y dé consejos, consuele al oído, pero también cuente chistes, haga reír a la misión, y reitere constantemente el tema de la pureza. Ser limpios de corazón es una de las enseñanzas centrales y en todos los rituales se enfatiza este tema. Como dijo Gerardo, una materia de mediana edad: "la religión de Fidencio es limpia". ${ }^{17}$

Los fidencistas realmente se sacrifican durante las fiestas: se quedan a dormir sobre el suelo en terrenos que muchas veces renta su materia, por lo que la cuestión sanitaria es siempre un problema. Varios de los rituales implican estar mezclados con polvo y suciedad, como rodar hasta la tumba de Fidencio, o ir al Cerro de las Campanas caminando (a cuatro kilómetros del pueblo), en medio del sol y el polvo del desierto. El ritual más impactante y lo que da la nota de contraste con el asunto de la limpieza es el que se celebra en el Charquito: el agua es lodosa, oscura y con olor a azufre. Los fieles entran al agua, rodeando a su materia; cada uno pasa frente a ella, quien en trance les dedica unas palabras para luego lanzarlos de espaldas hacia el agua lodosa. Los cuidadores sostienen a los fieles mientras dura la inmersión, repitiendo tres veces el ritual, acomodándolos después en su lugar en el círculo. Esto sucede en medio de cantos, risas y chistes entre la materia y sus fieles. El Charquito es el sitio clave para observar este ritual que podría llamarse de inversión: para los fidencistas es aquí donde se lavan las enfermedades y donde se resalta lo

${ }^{17}$ Entrevista a Paco, Irma Gerardo, 18 marzo del 2018. 
que me parece un reto al resto del mundo desde la periferia. La idea de pureza en el trance y manejo de energías contrasta con lo que ocurre en el Charquito: una suciedad que limpia.

Como remarcan Armendáriz y Alvarado:

El más preciado objeto que se le puede otorgar al Niño es el propio cuerpo, pues, al ser un intercesor entre Dios y el hombre, motiva que se busque la pureza del espíritu por medio del sacrificio corporal. El dolor causado por la penitencia se ve reflejado en los rostros de los peregrinos, que lucen sudorosos y ennegrecidos por la tierra (2007: 13).

Desde la época en que vivía Fidencio, Monterrey, la metrópoli regional, veía a Espinazo como un centro de "infección". Los periódicos insistían en que estaban "revueltos locos con apestados", y que "el contagio es inminente", ${ }^{18}$ haciendo alusión a los miles de enfermos -desde leprosos, tuberculosos y paralíticos-que acudían a buscar a Fidencio. Espinazo, un lugar considerado marginal, sucio y pobre, se sigue plantando con ritualidad propia frente a los representantes de la ciencia y el Estado, en franca rebeldía ante la definición de lo que para la metrópoli significa ser "limpio", "puro" o "inocente" (cf. Agostoni, 2018). El cuerpo, visto como putrefacto para unos, es limpiado en el Charquito, que aparenta suciedad, pero "en realidad" no lo es, es una fuente de limpieza para quien tiene fe en el Niño. ${ }^{19}$

\section{Travestismo e inclusividad}

La indeterminación y la ambigüedad son parte del fidencismo y también de lo que, me parece, causa a quienes lo estudiamos, que nos movemos entre la fascinación y la ansiedad. Como antropóloga educada en un catolicismo sobrio del centro-occidente de México, los rituales y la corporeidad fidencista me provocaban al mismo tiempo una inexplicable sensación de repulsión y atracción. Considero importante mencionarlo, porque nuestras categorías provienen siempre de esta relación intersubjetiva, pues, como afirma Jackson, es a través de otros patrones corporales como comprendemos nuevas experiencias y nuevas ideas, ya que nos devuelve a nuestro propio cuerpo y nuestro propio habitus (Jackson, 1983: 334).

La corporeidad en el fidencismo no se presenta fija y situada, sino en movimiento y desencializada. El género es un claro ejemplo de esto. Zavaleta (2016) se pregunta la razón por la cual en los cultos fidencistas "hay tantos homosexuales". Pienso que la pregunta desde las corporeidades puede, en todo caso, convertirse en qué es lo que contextualiza el fidencismo para que estas corporeidades tengan la posibilidad de expresarse.

En el trabajo de campo fueron notables las variadas manifestaciones de amaneramiento y travestismo. Fidencio, por ejemplo, muchas veces es encarnado por mujeres. A la Niña Aurorita siempre la vi personificada por hombres, aunque sé que también la personifican mujeres. Pancho Villa, representante de una masculinidad norteña acentuada, es muchas veces encarnado por mujeres, mientras que la gitana Margarita lo es exclusivamente por homosexuales (Carrizales, 2018).

Dos momentos del trabajo de campo (marzo 2017 y 2018) ilustran mejor este punto:

18 marzo 2017. La materia cae en trance y comienza a vestirse encima de su propia ropa (sombrero de campo, pantalón de mezclilla, camisa de cuadros y cinturón piteado) como Aurorita. La música norteña suena, la materia se quita el sombrero y comienza a ponerse un vestido de raso rosa, con holanes. Sigue bailando, se acomoda el sombrero de raso, también rosa. La columna lo rodea, también bailando o esperando que la materia comience su curación: la materia toma de la canasta decorada y llena de dulces un puño y los comienza a aventar a los asistentes. Los asistentes que pasan por ahí también entran al círculo a recoger dulces o aproximarse a la materia. La materia sigue bailando al compás de la música norteña, dando vueltas sobre sí mismo/a. Ahora toma a otro hombre de los asistentes y comienza la curación, siempre bailando y hablando con voz de niña. Lo soba, le pasa las manos por todo el cuerpo y finalmente se concentra en la espalda alta para sacarle el mal. Por fin, hace un gesto con las manos indicando que le sacó algo al paciente, quien se vuelve a reintegrar al círculo. La materia sigue bailando en trance.

17 marzo 2018. Las misas fidencistas se llevan a cabo en el teatro que utilizaba Fidencio para sus obras. Ariel recibe a varias columnas y los saluda desde este estrado, dando paso a la misa fidencista, la cual es organizada por los líderes de varias columnas. En el altar están tres mujeres con alba y estola, dirigiendo el oficio. Varios hombres las asisten, sentados alrededor del altar, alguno de ellos va maquillado y se nota su rango por estar junto

${ }^{18}$ Sobre el papel de los medios de comunicación en la difusión del fidencismo, véase Agostoni, 2018.

19 Entrevista a Paco, 18 marzo del 2018. 


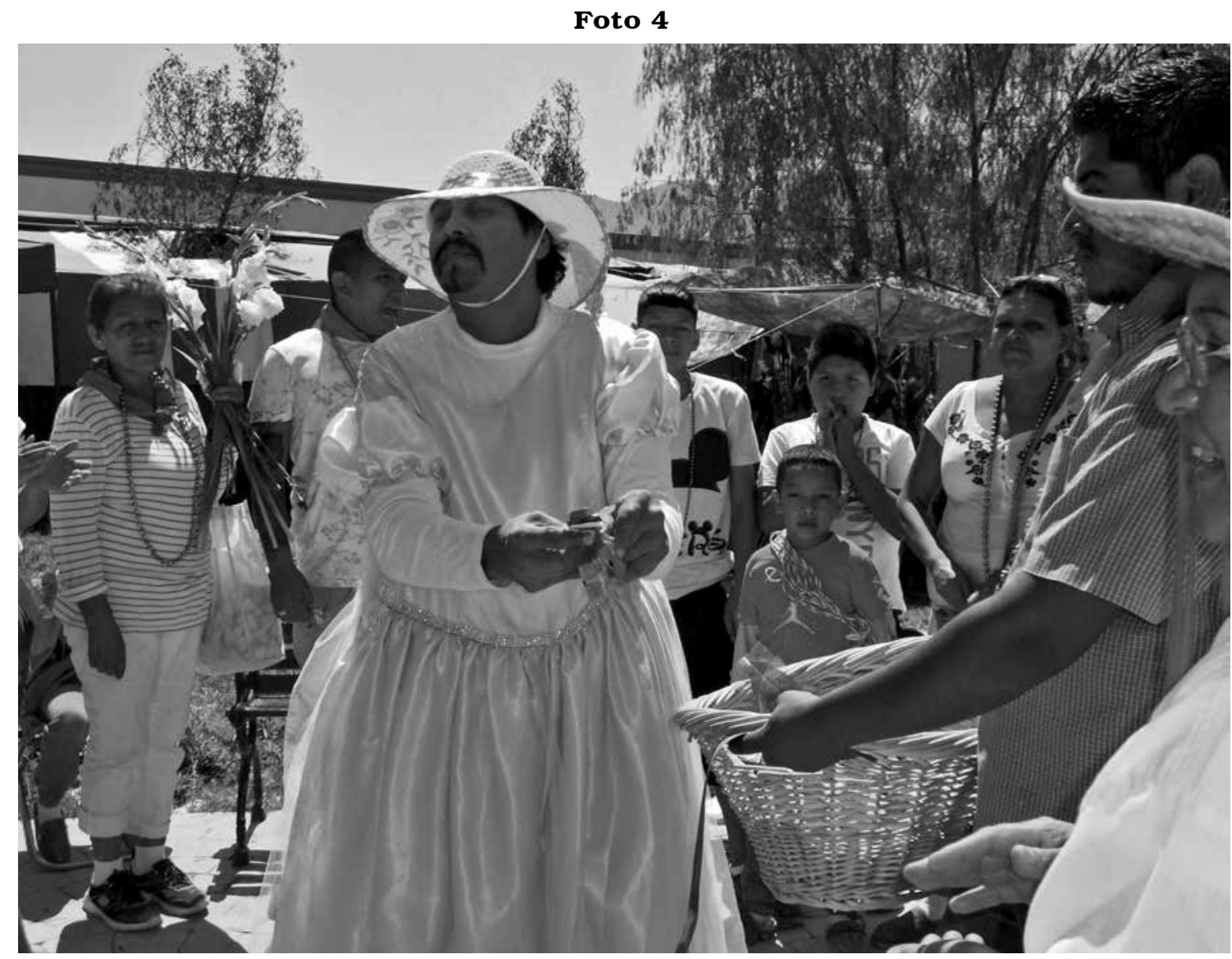

Materia de la Niña Aurorita en trance, sanando fieles Foto: Alejandra Aguilar Ros, marzo 2017

a las sacerdotisas y porque después las ayudan de cerca durante los rituales. La liturgia durante la misa me parece idéntica a la católica; de hecho, se utiliza un misal Se da la comunión, que me dice Ariel, no es el cuerpo y la sangre de Cristo, sino sólo una conmemoración. Antes, se realizó un lavado de pies corto. Todo el ritual dura bastante tiempo y mientras tanto, abajo del estrado, los asistentes podrían estar saludando, paseando, comiendo, en trance, saludando a Ariel y a Fabiola, tomándose fotos Es una fiesta. Llega el final de la misa, las sacerdotisas reparten bendiciones. Ariel pasa al frente y dice algunas palabras. Como yo estaba muy impactada con la liturgia dirigida por mujeres y hombres claramente afeminados, [...] las palabras de Ariel [adquirieron pleno sentido]: "esto es la fiesta del Señor y todo mundo puede participar, todo mundo entra, nadie es excluido, todo mundo come, a nadie se le niega nada”. La materia que liderea la misa dirige a un grupo de Monclova, Coahuila. Antes de bajar del altar, comienza la música y entra en trance; se enfila a la parte de atrás del salón donde hay unas escaleras. Las sube y junto con otro materia que traía otra misión -era el mismo que vi bailando a la Niña Aurorita el año pasado-aventaron frutas, dulces y juguetes -la limosna, le llaman-, a toda su gente. La materia baja, tocando a su paso a la gente en la cabeza, les abraza y habla al oído -incluyéndome-, cuando comienza el baile con música regional norteña. Alrededor de la materia nos congregamos y ella toma a algunos de los presentes y baila con ellos, abrazándolos, acariciándoles, ofreciendo palabras de consuelo al oído y llorando con ellos. Caigo en la cuenta de lo emocional que es el culto, donde, en lo cotidiano, el desierto no deja espacio para gastar energía en expresar emociones, pues todos los recursos deben ser aprovechados racionalmente. Aquí, en Espinazo, todo es generosidad: de los frutos que se repartieron, de los abrazos, de las lágrimas.

\section{Reflexiones finales: el lado B del noreste}

Estos procesos corporizados se derivan de un entorno donde emergen como problemáticas que las materias comparten debido a posiciones históricas, de clase y de sistema de género. El análisis fenomenológico nos revela en los fidencistas una disposición corporeizada 
alternativa y fluida en la que aparecen a través del trance temas contrastantes como la educación vs. la falta de ella entre los marginados, la limpieza e inocencia en rituales en los que se sufre ensuciándose, o la indeterminación del género. Esta corporeidad tiene como contexto la región del noreste de México.

El noreste, en cuanto parte de ese norte indómito de una república a la que se sumó de manera reticente, se ha configurado como un territorio particular. Es a partir de la guerra México-Estados Unidos (1846-1848) que algunos autores identifican que este territorio se conforma como un espacio de héroes bélicos, asociados a deseos de resistencia y desquite (Arias y Durand, 2009), y habitado por migrantes atraídos a este espacio que entretejió nuevas formas de relaciones en ambos lados de la frontera México-Estados Unidos. Si bien por el momento no entraré en la discusión de la noción de frontera, es indudable que este "nuevo" territorio constituía formas de relación propias y muy diversas, que implican una relación, de maneras particulares, con el desierto y sus recursos (Alvarado Solís, 2011; Armendáriz y Alvarado, 2007). Diversos flujos de inmigrantes, poblaciones locales indígenas y el convulso ambiente histórico hicieron del norte un lugar de grandes contrastes. A este contexto se añade el fuerte influjo de las comunicaciones del tiempo: la expansión de las líneas de ferrocarril aunado al gran impulso nacional de los medios de comunicación (ferrocarril, prensa y fotografía), los cuales ayudaron a redefinir una nueva espacialidad (Arias y Durand 2009: 11; Agostoni, 2018).

Todo ello convertía esta zona en un caldo de cultivo apto para el surgimiento de devociones con referentes que incorporaban las condiciones sociales de tensión social, de marginación, injusticia, arbitrariedad, discriminación e inseguridad en la vida de muchos de los viejos y nuevos pobladores de la frontera a finales del siglo XIX (Arias y Durand 2009: 22).

Hoy es otro contexto histórico, pero su herencia resuena. Quienes visitan Espinazo siguen siendo los marginales, los pobres, los reprimidos en su expresión de género, los carentes de servicios médicos o escasa salud. Es aquí donde se comprende la transmisión de conocimientos corporales, que aparecen como contrastes. En un ejército de fieles pobres y escasamente educados, el acento puesto en el conocimiento sobre lo esencial del fidencismo sigue siendo enfatizado por las materias de más experiencia como algo que debe estudiarse y profundizarse -algo que es reforzado en su lado institucional por la IFC-. Sin embargo, el trance permite que las enseñanzas puedan adaptarse a las materias y, a la vez, ser contestatarias desde su propia situación.
Esta ambigüedad fluida posibilita una transmisión corporeizada de conocimientos, resistencias y descentralizaciones del cuerpo, que hacen que el fidencismo siga vigente y permita a grupos sociales periféricos visibilizarse. De hecho, no sólo los permite, sino que los anima y posiciona centralmente. Zavaleta (2018) documenta que en los años ochenta había muchas mujeres jefas de familia que eran materias, lo cual era relevante en aquel momento. Hoy no podría decir que las mujeres predominan, pero es notable cómo la corporalidad fidencista permite acceder a espacios corporales distintos a los que la identidad marcada por la clase social, el físico y las preferencias identitarias constriñen, al tiempo que posibilita el acceso a lo sagrado visto como puro e inocente.

La corporalidad fidencista es más fluida que lo admitido por el contexto representativo del norte. Al dejar entrar diversos espíritus, la materia en trance y sus seguidores tienen la posibilidad de ampliar el habitus corporal prescrito, pues el fidencismo provee un espacio y canales para que las lágrimas, las risas y los sentimientos puedan expresarse, en un contexto donde no es tan permitido. El noreste, usualmente representado como rudo, económicamente fuerte, materialista, macho, da lugar a la realidad de la pobreza, la emoción y la expresión de género fluctuante. Así, el fidencismo es una religión que ayuda a expresar los males profundos del abandono, del desprecio, de la autoestima. Los contrastes presentados en los rituales y los espíritus corporizados lo recuerdan una y otra vez: Pancho Villa manifestado en el cuerpo de una mujer; Margarita la gitana, en el de un muchacho homosexual; la Niña Aurorita en el cuerpo de un hombre de 1.80 metros, fornido y con ropa de ranchero del norte; el discurso de limpieza y purificación dentro de los rituales en el Charquito que huele a agua sulfurosa y deja a todos sus participantes cubiertos de lodo.

El trance hace que este culto no contenga un solo centro sagrado fijo; es movible en la condición de ubicuidad de los cuerpos de las materias, y hace que los cuerpos sean santuarios que "migran" con sus devotos, recreando la compañía de Fidencio y reproduciendo una zona cultural que tiene una tradición histórica de espiritualidad místico-espiritista.

El que Pancho Villa se manifieste en Espinazo es también revelador, ya que una de las imágenes que los fidencistas retoman continuamente es la de un ejército. Villa nunca pasó por este lugar en específico, pero una materia mencionó que Villa aparece aquí porque en la Revolución su ejército no se quiso quedar a ayudar a Fidencio. Este ejército, que luchaba por una causa revolucionaria a favor de los pobres, nunca les cumplió, al menos en el noreste. Pero ahora Villa no 
tiene más opción que cumplirles. El contraste de fortaleza/debilidad del ejército de Pancho Villa aparece resuelto en Espinazo. Fidencio siempre se escapa para aparecer en otro cuerpo y en otros lugares, obligando a los poderosos, como Villa, los De la Fuente o los médicos incrédulos, a llegar a su propio espacio y, en ocasiones, quedarse.

\section{Fuentes}

Agostoni, Claudia

2018 "Ofertas médicas, curanderos y la opinión pública: el Niño Fidencio en el México posrevolucionario", en Anuario Colombiano de Historia Social y de la Cultura, vol. 45, núm. 1, pp. 215-243.

Aguilar Ros, Alejandra

En prensa "De cuerpo y corporeidades religiosas: una aproximación a los estudios del cuerpo en el campo religioso en México", artículo en revisión para su publicación por el Centro de Investigaciones y Estudios Superiores en Antropología Social/El Colegio de San Luis.

Alvarado Solís, Neyra

2011 "Peregrinos y ancestros en los laberintos del desierto mexicano", en Neyra Alvarado, María Isabel Mora y Javier Maisterrena (coords.), Huellas en el desierto. Trabajo y ritual en el norte de México, El Colegio de San Luis (Investigaciones), San Luis Potosí, pp. 253-275.

ARIas, Patricia y Jorge Durand

2009 "Migraciones y devociones transfronterizas", en Migración y Desarrollo, núm. 12, pp. 5-26.

Armendáriz, Lorenzo y Neyra Alvarado

2007 El campo del dolor, Artes de México/Secretaría de Cultura y Artes Ciudad de México, México.

Berlanga, José Luis, Eric Lara

y César Augusto Ramírez

1999 Las fiestas del dolor; un estudio sobre las celebraciones del Niño Fidencio, Fondo Estatal para la Cultura y las Artes de Nuevo León, Monterrey.

Bourdieu, Pierre

1977 Outline of a Theory of Practice, Cambridge University Press, Cambridge.

Carrizales Márguez, Janeth

2018 "Panorama general de la fiesta fidencista de Espinazo, Nuevo León”, en Fuentes Humanísticas, año 30, núm. 56, enero-junio, pp. 35-46 <http: / fuenteshumanisticas.azc.uam.mx/ index.php/rfh/article/view/896> [30 marzo 2019].

Chua, Liana

2011 "Soul encounters: emotions, corporeality, and the matter of belief in a Bornean village", en Social Analysis, vol. 55, núm. 3, invierno, pp. 1-17.

CSORDAS, THOMAS

1990 "Embodiment as a Paradigm for Anthropology", en Ethos, vol. 18, núm. 1, pp. 5-47.
Csordas, ThOMAS

1994 "Introduction: The body as representation and being-in-the-world", en Thomas Csordas (ed.), Embodiment and Experience: The Existential Ground of Culture and Self, Cambridge University Press, Cambridge, pp. 1-24.

Csordas, ThOMAS

2010 "Modos somáticos de atención", en Silvia Citro (coord.), Cuerpos plurales: antropología de y desde los cuerpos, Biblos, Buenos Aires, pp. 83-104.

De Ita Rubio, Beatriz

2018 "Tradición y sincretismo en las curaciones del 'Niño' Fidencio y los fidencistas", en Entorno, año 18, núm. 48, enero-junio, pp. 16-19 <https://www.uanl.mx/utilerias/ publicaciones/entorno/entorno_48.pdf> [19 abril 2019].

FARFÁn, Olimpia

1997 Elfidencismo, una curación espiritista, Gobierno del Estado de Nuevo León-Archivo General del Estado (Orgullosamente Bárbaros), Monterrey.

Garza Quirós, Fernando

1974 El Niño Fidencio y el fidencismo, Oasis, México. González Vidales, Pedro Ángel

1970 Vida y milagros de El Niño Fidencio, Impresiones del Norte, Saltillo.

JACKSON, MichAEL

1983 "Knowledge of the body", en Man, vol. 18 núm. 2, pp. 327-345 <https://www.jstor. org/stable/2801438> [18 abril 2019].

Macklin, Barbara June

1967 "El Niño Fidencio: un estudio del curanderismo en Nuevo León", en Humanitas. Anuario del Centro de Estudios Humanísticos de la Universidad de Nuevo León, vol. 8, pp. 529. 563.

Mauss, MARCEL

1979 Las técnicas del cuerpo, Tecnos, Madrid [1936].

Merlau-Ponty, Maurice

1962 Phenomenology of Perception, Routledge and Kegan Paul, Londres.

Monsiváis, CARLOS

1995 Los rituales del caos, Era, México.

Zavaleta, Antonio NoÉ

2012 "La transmigración de la religión popular: práctica y renovación de creencias sincréticas a través de la frontera México-Estados Unidos de América”, en Sociedad, Estado y Territorio, vol. 1, núm. 1(2), julio-diciembre, pp. 7-27.

Zavaleta, Antonio Noé

2013 El Niño Fidencio: libro de las Sagradas Escrituras, AuthorHouse, Bloomington.

Zavaleta, Antonio Noé

2016 El Niño Fidencio and the Fidencistas: Folk Religion in the U.S. Mexican Borderland. AuthorHouse, Bloomington.

Zavaleta, Anthony

2018 "El Niño Fidencio y los fidencistas", en $\mathrm{Dr}$. Tony Zavaleta. U.S. Mexico Border Antropologist <http: / /drtonyzavaleta.com/es/el-ninofidencio-y-los-fidencistas / $>[14$ de mayo 2019]. 